Tropical Journal of Pharmaceutical Research March 2015; 14 (3): 503-509

ISSN: $1596-5996$ (print); 1596-9827 (electronic)

(C) Pharmacotherapy Group, Faculty of Pharmacy, University of Benin, Benin City, 300001 Nigeria.

All rights reserved.

Available online at http://www.tjpr.org

Original Research Article

http://dx.doi.org/10.4314/tjpr.v14i3.20

\title{
Antioxidant Activities of Methanol Extract and Solvent Fractions of Marine Macroalga, Avrainvillea erecta (Berkeley) A. Gepp and E.S. Gepp (Dichotomosiphonaceae)
}

\author{
Tsun-Thai Chai ${ }^{1,2 *}$, Meng-Tee Kwek ${ }^{2}$, Nor Ismaliza Mohd Ismail ${ }^{1,3}$, Jillian Lean \\ Sim Ooi ${ }^{4}$, Affendi Yang Amri ${ }^{5}$, Fazilah Abd Manan ${ }^{6}$, Yew-Chye Law ${ }^{2}$ and Fai- \\ Chu Wong ${ }^{1,2}$
}

${ }^{1}$ Centre for Biodiversity Research, ${ }^{2}$ Department of Chemical Science, Faculty of Science ${ }^{3}$ Department of Biological Science, Faculty of Science, Universiti Tunku Abdul Rahman, 31900 Kampar, ${ }^{4}$ Department of Geography, Faculty of Arts and Social Sciences Building, 5 Institute of Biological Sciences, Faculty of Science, University of Malaya, 50603 Kuala Lumpur, ${ }^{6}$ Department of Biosciences and Health Sciences, Faculty of Biosciences and Medical Engineering, Universiti Teknologi Malaysia, 81310 UTM Johor Bahru, Malaysia

*For correspondence: Email: chaitt@utar.edu.my; Tel: +605-468 8888 ext 4516

Revised accepted: 9 February 2015

\begin{abstract}
Purpose: To determine the antioxidant activity of methanol extract (ME) and solvent fractions of Avrainvillea erecta as well as their total phenolic and flavonoid contents.

Methods: The antioxidant activities of ME as well as its chloroform, butanol, and aqueous fractions (CF, $B F$ and WF, respectively) of $A$. erecta were evaluated via 2,2-diphenyl-1-picrylhydrazyl (DPPH), nitric oxide (NO) and hydrogen peroxide $\left(\mathrm{H}_{2} \mathrm{O}_{2}\right)$ scavenging assays as well as ferric reducing antioxidant power (FRAP) assay. Total phenolic and flavonoid contents were determined spectrophotometrically.

Results: CF and BF possessed equally high DPPH scavenging activity with half-maximal effective concentration ( $\left.E C_{50}\right)$ of 535 and $532 \mathrm{mg} / \mathrm{ml}$, respectively. CF had stronger NO scavenging activity ( $E C_{50}$ $743 \mu \mathrm{g} / \mathrm{mL}$ ) than $\mathrm{ME}$ and $\mathrm{BF}$, although weaker compared with quercetin $\left(E_{50} 279 \mu \mathrm{g} / \mathrm{ml}\right)$. CF also produced the highest FRAP value $\left(451 \mu \mathrm{mol} \mathrm{Fe}^{2+} / \mathrm{g}\right)$ among all samples examined. Notably, $\mathrm{H}_{2} \mathrm{O}_{2}$ scavenging activity was only found in $C F\left(E C_{50} 387 \mu g / m l\right)$, which was as strong $(p>0.05)$ as that of gallic acid $\left(E C_{50} 456 \mu \mathrm{g} / \mathrm{mL}\right)$. BF had the highest total phenolic content while CF had the highest total flavonoid content.

Conclusion: CF of A. erecta, which has the highest flavonoid content of all the extracts evaluated, is a potential source of natural antioxidants, especially hydrogen peroxide scavengers.
\end{abstract}

Keywords: Antioxidant, Avrainvillea erecta, Flavonoid, Macroalga, Phenolic

Tropical Journal of Pharmaceutical Research is indexed by Science Citation Index (SciSearch), Scopus, International Pharmaceutical Abstract, Chemical Abstracts, Embase, Index Copernicus, EBSCO, African Index Medicus, JournalSeek, Journal Citation Reports/Science Edition, Directory of Open Access Journals (DOAJ), African Journal Online, Bioline International, Open-J-Gate and Pharmacy Abstracts

\section{INTRODUCTION}

Marine macroalgae, also known as seaweeds, are consumed as foods in many countries. Traditionally, some macroalgae are used as gelling agent and stabilisers for the food and pharmaceutical industries [1]. Macroalgaederived bioactive extracts and compounds are known to have health-promoting and therapeutically relevant activities [2]. Consequently, there is great interest worldwide to discover bioactive metabolites from macroalgae with the goals of using them as active ingredients in functional food/nutraceutical and pharmaceuticals production [3]. 
Synthetic antioxidants have wide applications in the food, pharmaceutical and cosmetic industries $[4,5]$. The search for potent natural antioxidants to be used as alternatives to synthetic antioxidants has intensified over the past decades due to concerns for the toxicity of synthetic antioxidants [6]. In this context, the exploration of macroalgae for natural antioxidants is relevant to current research interest and need of society. Macroalgae are classified into three main groups: Phaeophyta (brown seaweeds), Rhodophyta, (red seaweeds) and Chlorophyta (green seaweeds) [7]. Generally, the green seaweeds have the greatest phenolic contents and antioxidant activities among the three macroalgae groups [1]. In an extensive comparison of 48 macroalga species [8], the organic extract of green seaweed Avrainvillea longicaulis was found to have antioxidant activity superior or equivalent to that of commercial antioxidants (butylated hydroxytoluene, butylated hydroxyanisole and alpha-tocopherol). Antioxidant activities have also been discovered from extracts of other green macroalgae [9]. Cymopol, 7hydroxycymopol and avrainvilleol are examples of antioxidant compounds isolated from green seaweeds [10].

This study focused on the antioxidant activity of A. erecta, a common tropical green seaweed. Except for a strong hemagglutination activity [11] and weak blood anticoagulant activity [12] detected in $A$. erecta extracts, no other bioactivities have been reported for the species. Extracts and compounds isolated from other Avrainvillea species have been found to exhibit antioxidant activity [10]. It is therefore likely that $A$. erecta may also contain potent natural antioxidants. Hence, this study aimed to analyse the antioxidant activity of the methanol extract and solvent-partitioned fractions of $A$. erecta. Furthermore, total phenolic and flavonoid contents of the extract and fractions were also quantified to determine if these phytochemical parameters were related to the antioxidant properties of the samples.

\section{EXPERIMENTAL}

\section{Alga sample}

Specimens of marine macroalga Avrainvillea erecta (Berkeley) A. Gepp and E.S. Gepp (Family Dichotomosiphonaceae) were collected by SCUBA diving to depths of $3-6 \mathrm{~m}$ in the South China Sea off the Southwest shore of Tinggi Island, Malaysia, in August 2013. Collected specimens were washed with seawater to remove sands and debris before they were frozen. Upon arrival at the laboratory, the specimens were lyophilised and then pulverised using a Waring blender.

\section{Methanol extraction of $\boldsymbol{A}$. erecta}

The alga powder $(20 \mathrm{~g})$ was suspended in 600 $\mathrm{ml}$ of absolute methanol. The mixture was shaken on an orbital shaker (200 rpm) at room temperature for 72 hours. Next, the mixture was vacuum filtered. The filtrate collected was concentrated under reduced pressure at $37{ }^{\circ} \mathrm{C}$ using a rotary evaporator. The concentrated filtrate was then oven-dried to yield a solid methanol extract (ME). For antioxidant and phytochemical assays, ME (280 mg) was dissolved in dimethyl sulphoxide (DMSO), aliquoted and stored at $-20{ }^{\circ} \mathrm{C}$ until used.

\section{Solvent partitioning of ME}

Solid ME extract of $A$. erecta (400 mg) was suspended in $50 \mathrm{~mL}$ of deionised water and then partitioned sequentially with equal volume of chloroform then n-butanol to yield chloroform fraction (CF), n-butanol fraction (BF) and water fraction (WF) using a separating funnel. CF and BF were concentrated with rotary evaporation at $45^{\circ} \mathrm{C}$ and then oven-dried at $37^{\circ} \mathrm{C}$ to constant weight. WF was freeze-dried. To prepare for antioxidant and phytochemical assays, the solid residues of the fractions were dissolved in different concentrations of DMSO (for CF and $\mathrm{BF}$ ) or deionised water (for WF).

\section{Evaluation of 2, 2-diphenyl-1-picrylhydrazyl (DPPH) radical scavenging activity}

DPPH radical scavenging activity of the methanol extract and various solvent fractions was determined by a previously reported assay protocol [13] with slight modification. A mixture of $120 \mu \mathrm{L}$ of sample $(0,0.25,0.50,0.75,1.00,1.50$ $\mathrm{mg} / \mathrm{ml})$ and $200 \mu \mathrm{l}$ of DPPH $(0.004 \%$ in absolute methanol) was incubated in darkness for $30 \mathrm{~min}$ at room temperature. The absorbance of the mixture was measured at $517 \mathrm{~nm}$. DPPH radical scavenging activity (S) was calculated as in Eq 1.

$S(\%)=\{1-(\mathrm{As} / \mathrm{Ac})\} 100$

where As is the absorbence in the presence of an extract or fraction, whereas Ac is the absorbance of the control reaction where the extract or fractions were omitted. A reaction blank was prepared for each measurement by replacing DPPH with methanol. Quercetin was used as the positive control. Half maximal effective concentration $\left(E_{50}\right)$ is defined as the 
sample concentration required to achieve $50 \%$ of radical scavenging activity.

\section{Evaluation of nitric oxide (NO) scavenging activity}

NO scavenging activity was determined using a microplate assay modified from the assay protocol described previously [14]. NO was generated by using an illuminated sodium nitroprusside (SNP) solution. Briefly, $100 \mu \mathrm{L}$ of sample was mixed with $100 \mu \mathrm{L}$ of $3 \mathrm{mM} \mathrm{SNP}$ and incubated for 30 min under illumination. Next, 50 $\mu \mathrm{L}$ of Griess reagent was added to the mixture, followed by a further incubation for $10 \mathrm{~min}$ in darkness. The absorbance of mixture was measured at $546 \mathrm{~nm}$. NO scavenging activity $(\mathrm{N})$ was calculated according to Eq 2.

$N(\%)=\{1-(\mathrm{As} / \mathrm{Ac})\} 100$

As is the absorbance in the presence of an extract or fraction, whereas Ac is the absorbance of the control reaction where the extract or fractions were omitted. A reaction blank was prepared for each measurement by omitting SNP. Quercetin was used as the positive control. $E_{50}$ is defined as the sample concentration required to achieve $50 \%$ of NO scavenging activity.

\section{Determination of hydrogen peroxide $\left(\mathrm{H}_{2} \mathrm{O}_{2}\right)$ scavenging activity}

$\mathrm{H}_{2} \mathrm{O}_{2}$ scavenging activity was evaluated as previously described [15], with minor modifications. Briefly, $0.2 \mathrm{ml}$ of sample and $1 \mathrm{ml}$ of $10 \mathrm{mM} \mathrm{H} \mathrm{O}_{2}$ was mixed and allowed to stand for $10 \mathrm{~min}$ at room temperature. Then, absorbance of the mixture was read at $230 \mathrm{~nm}$. $\mathrm{H}_{2} \mathrm{O}_{2}$ scavenging activity $(\mathrm{H})$ was calculated using Eq 3.

$H(\%)=\{1-($ As/Ac $)\} 100$

As is the absorbance in the presence of an extract or fraction, whereas Ac is the absorbance of the control reaction where the extract or fractions were omitted. A reaction blank was prepared for each measurement by omitting $\mathrm{H}_{2} \mathrm{O}_{2}$. Gallic acid was used as the positive control. $E_{50}$ is defined as the sample concentration required to achieving $50 \%$ of $\mathrm{H}_{2} \mathrm{O}_{2}$ scavenging activity.

\section{Ferric reducing antioxidant power (FRAP) assay}

FRAP values of the extract and fractions were assessed using a microplate assay described in
[13] with slight modification. Briefly, a mixture of $40 \mu \mathrm{l}$ of sample and $240 \mu \mathrm{l}$ of FRAP reagent was incubated at $37^{\circ} \mathrm{C}$ for $5 \mathrm{~min}$. The FRAP reagent consisted of sodium acetate buffer $(300 \mathrm{mM}, \mathrm{pH}$ 3.6), 2,4,6-tripyridyl-s-triazine $(10 \mathrm{mM})$, and $\mathrm{FeCl}_{3} \cdot 6 \mathrm{H}_{2} \mathrm{O}(20 \mathrm{mM})$ at a 10:1:1 (v:v:v) ratio. The absorbance of the mixture was measured at 593 $\mathrm{nm}$. FRAP values are presented in $\mathrm{mM} \mathrm{Fe}{ }^{2+}$ equivalents, calculated from a standard curve prepared with $\mathrm{FeSO}_{4} \cdot 7 \mathrm{H}_{2} \mathrm{O}$. Ascorbic acid (10 $\mu \mathrm{g} / \mathrm{ml}$ ) was used as the positive control.

\section{Determination of total phenolic content}

Total phenolic (TP) content was determined by Folin-Ciocalteu method [16], modified into a microplate format. A mixture of $40 \mu$ of sample (ME, CF, BF or WF), $160 \mu \mathrm{l}$ of deionised water and $20 \mu \mathrm{l}$ of Folin-Ciocalteu reagent was incubated at room temperature for $3 \mathrm{~min}$. Next, $60 \mu \mathrm{l}$ of $20 \%$ sodium carbonate was added to the reaction mixture, followed by a further incubation of $120 \mathrm{~min}$. Absorbance of the mixture was read at $765 \mathrm{~nm}$. TP contents of samples were expressed in $\mathrm{mg}$ gallic acid equivalents (GAE) per gram of sample, calculated from a standard curve prepared with 0 to $100 \mu \mathrm{g} / \mathrm{ml}$ gallic acid.

\section{Determination of total flavonoid content}

Total flavonoid (TF) content was determined using aluminium chloride colorimetric assay [17], modified into a microplate format. A mixture of 20 $\mu \mathrm{l}$ of sample (ME, CF, BF or WF), $60 \mu \mathrm{l}$ of $95 \%$ ethanol, $20 \mu \mathrm{l}$ of $10 \%$ aluminium chloride hexahydrate, $20 \mu \mathrm{l}$ of $1 \mathrm{M}$ potassium acetate and $160 \mu \mathrm{l}$ of deionised water was incubated at room temperature for $30 \mathrm{~min}$. Then the absorbance of the reaction mixture was determined at $415 \mathrm{~nm}$. Blank reaction was prepared by replacing aluminium chloride hexahydrate with water. TF contents of the samples were expressed in $\mathrm{mg}$ quercetin equivalents (QE) per gram of sample, calculated from a standard curve prepared with 0 to $500 \mu \mathrm{g} / \mathrm{ml}$ quercetin.

\section{Data analysis}

Experiments were carried out in triplicates and data reported are mean \pm standard error of the mean (SEM). Statistical analysis was performed by using Statistical Analysis System (SAS) software (version 9.3). Data were analysed by one-way ANOVA test followed by Fisher's least significant difference (LSD) test, or using Student's t-test where appropriate, at a probability level of 0.05 . Linear regression analysis was carried out using Microsoft Office Excel 2010. 


\section{RESULTS}

In this study, methanol extraction of $20 \mathrm{~g}$ of freeze-dried $A$. erecta led to the production of $681.2 \mathrm{mg}$ of ME (3.4 \% yield). Solvent partitioning of ME $(400 \mathrm{mg})$ yielded 16.3, 58.2 and $252.5 \mathrm{mg}$ of $\mathrm{CF}, \mathrm{BF}$, and $\mathrm{WF}$, respectively, representing $4.08,14.55,63.13 \%$ yield. Owing to limited sample yields, we have begun our investigation with a preliminary assessment of the antioxidant activity of ME, CF, BF and WF at the sample concentration of $1 \mathrm{mg} / \mathrm{ml}$.

Table 1 presents the radical scavenging activities and ferric reducing ability of ME and its solvent fractions. $\mathrm{CF}$ and $\mathrm{BF}$ had $\mathrm{DPPH}$ radical scavenging activity 3 - and 5-fold higher than those of ME and WF, respectively. The strongest NO scavenging activity was found in CF, followed by $\mathrm{BF}, \mathrm{ME}$ and $\mathrm{WF}$. CF was the strongest $\mathrm{H}_{2} \mathrm{O}_{2}$ scavenger among the four samples tested. Notably, the $\mathrm{H}_{2} \mathrm{O}_{2}$ scavenging activity of CF was only slightly lower than that of positive control gallic acid. At the concentration of $1 \mathrm{mg} / \mathrm{ml}$, WF showed no $\mathrm{H}_{2} \mathrm{O}_{2}$ scavenging activity. ME and its fractions showed ferric reducing ability, with FRAP values ranging from 17.43 to $450.95 \mu \mathrm{mol} \mathrm{Fe}^{2+} / \mathrm{g}$. CF exhibited the highest FRAP value, followed by $B F, M E$ and lastly WF. All samples had lower FRAP values compared with ascorbic acid.

Our results show that $\mathrm{CF}$ had the highest radical scavenging and ferric reducing activities compared with $\mathrm{ME}$ and other fractions. By contrast, WF consistently had the lowest antioxidant activity based on the four parameters presented in Table 1. Hence, we proceeded to evaluate whether $\mathrm{ME}, \mathrm{BF}$ and $\mathrm{CF}$ exhibited antioxidant activities in a concentrationdependent manner.

$\mathrm{ME}, \mathrm{CF}$ and BF showed concentrationdependent effects in their DPPH radical scavenging (data not shown) and NO scavenging (Fig 1) activities within the range of concentrations tested. Only $\mathrm{CF}$ showed concentration-dependent $\quad \mathrm{H}_{2} \mathrm{O}_{2} \quad$ scavenging activity, which was also similar to that of gallic acid (Fig 2). We found no concentrationdependent $\mathrm{H}_{2} \mathrm{O}_{2}$ scavenging activity in ME and $\mathrm{BF}$ up to the sample concentration of 1000 $\mu \mathrm{g} / \mathrm{ml}$.

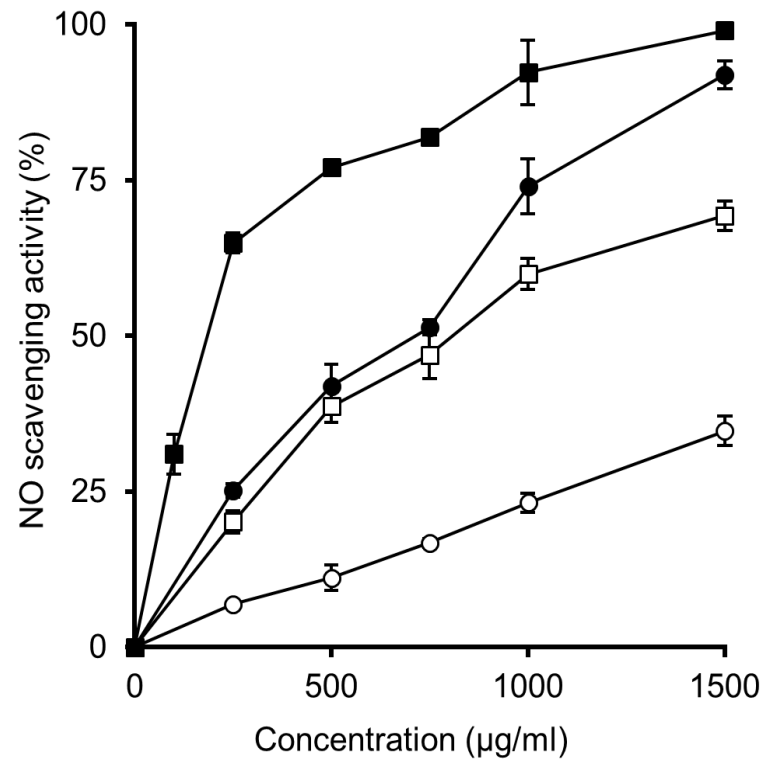

Fig. 1: Nitric oxide (NO) scavenging activities of $A$. erecta methanol extract $(\circ)$, chloroform fraction $(\bullet)$, and butanol fraction ( $\square$ ) compared with quercetin ( $\mathbf{\square})$. Data are mean \pm SEM $(n=3)$

Table 1: Radical scavenging activities and ferric reducing antioxidant power of $A$. erecta extract and fractions (1 $\mathrm{mg} / \mathrm{ml}$ )

\begin{tabular}{lcccc}
\hline Sample & \multicolumn{2}{c}{ Radical scavenging activity (\%) } & $\begin{array}{c}\text { Ferric reducing } \\
\text { antioxidant power }(\boldsymbol{\mu m o l} \\
\left.\mathbf{F e}^{2+} / \mathbf{g}\right)\end{array}$ \\
\cline { 2 - 4 } scavenging & NO scavenging & $\begin{array}{c}\mathbf{H}_{2} \mathbf{O}_{2} \\
\text { scavenging }\end{array}$ & $83 \pm 4^{*}$ \\
ME & $27.6 \pm 1.3^{*}$ & $23.2 \pm 1.6^{*}$ & $1.1 \pm 0.1^{*}$ & $451 \pm 10^{*}$ \\
CF & $85.5 \pm 0.9^{*}$ & $74.0 \pm 4.4$ & $94.5 \pm 0.9^{*}$ & $270 \pm 12^{*}$ \\
BF & $86.5 \pm 1.2^{*}$ & $59.9 \pm 2.5^{*}$ & $4.3 \pm 1.9^{*}$ & $17 \pm 3^{*}$ \\
WF & $16.9 \pm 0.2^{*}$ & $4.9 \pm 1.6^{*}$ & - & $25236 \pm 128$ \\
Positive & $97.9 \pm 0.2$ & $92.23 \pm 5.1$ & $99.8 \pm 0.2$ & (Ascorbic Acid) \\
control & (Quercetin) & (Quercetin) & (Gallic acid) & (
\end{tabular}

Data are presented as mean \pm SEM $(n=3)$. * indicates mean values that are significantly different $(p<0.05)$ from that of the positive control, as determined by Student's T-test. -, $\mathrm{H}_{2} \mathrm{O}_{2}$ activity was undetectable 


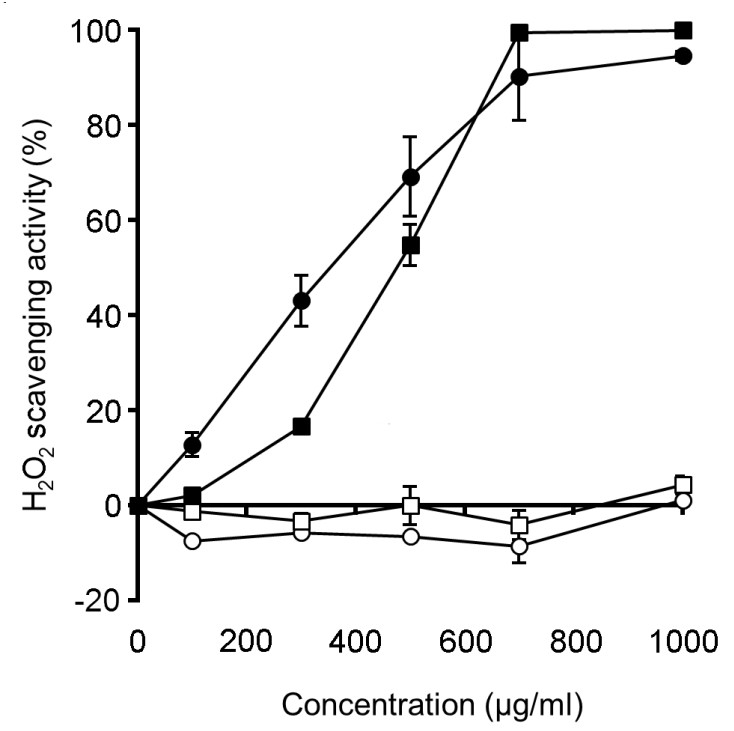

Fig. 2: Hydrogen peroxide $\left(\mathrm{H}_{2} \mathrm{O}_{2}\right)$ scavenging activities of $A$. erecta methanol extract (०), chloroform fraction $(\bullet)$, and butanol fraction $(\square)$ compared with gallic acid $(\square)$. Data are mean $\pm \operatorname{SEM}(n=3)$

For DPPH scavenging activity, the similar $\mathrm{EC}_{50}$ values of $\mathrm{CF}$ and $\mathrm{BF}$ were about 3-fold lower compared with ME, but 89-fold higher compared with quercetin (Table 2). For NO scavenging activity, CF had lower $\mathrm{EC}_{50}$ value than ME and $\mathrm{BF}$. The $\mathrm{EC}_{50}$ value of $\mathrm{CF}$ was about 2.7-fold higher compared with quercetin. Notably, $\mathrm{CF}$ and gallic acid had similar $\mathrm{EC}_{50}$ values for $\mathrm{H}_{2} \mathrm{O}_{2}$ scavenging activity. For $\mathrm{H}_{2} \mathrm{O}_{2}$ scavenging activity, $\mathrm{EC}_{50}$ values of $\mathrm{ME}$ and $\mathrm{BF}$ were not determined due to their lack of concentrationdependent effects (Fig 2).
TP contents of the extract and fractions, ranked in decreasing order, are: $\mathrm{BF}>\mathrm{CF}>\mathrm{ME}>\mathrm{WF}$ (Table 3). BF contained about 11-fold higher TP content compared with WF. TF contents of the extract and fractions, in descending order, are: $\mathrm{CF}>\mathrm{BF}>\mathrm{ME}>\mathrm{WF}$ (Table 3). TF contents of $\mathrm{CF}$ and BF were about 88- and 64-fold greater, respectively, in comparison with WF.

\section{DISCUSSION}

Our study demonstrated that methanol extract and solvent fractions of $A$. erecta possessed DPPH, $\mathrm{NO}$ and $\mathrm{H}_{2} \mathrm{O}_{2}$ scavenging activities as well as ferric reducing ability. Reports of the antioxidant activities of extracts or natural products derived from Avrainvillea species are very limited in the literature. Till date, antioxidant activity has only been reported for one Avrainvillea species, namely $A$. longicaulis $[8,10,18]$. To the best of our knowledge, this is the first report of antioxidant activities in the extract of $A$. erecta.

In this study, CF stood out as the fraction with the most potent antioxidant activity. $\mathrm{CF}$ was the strongest $\mathrm{NO}$ and $\mathrm{H}_{2} \mathrm{O}_{2}$ scavenger as well as the best reducing agent. $\mathrm{CF}$, together with $\mathrm{BF}$, also had the equally strongest DPPH radical scavenging activity. The reducing and DPPH scavenging activities of CF were less potent than the natural antioxidants we used as positive controls in this study. This observation is similar to that reported for $A$. longicaulis [8].

Table 2: $\mathrm{EC}_{50}$ values of radical scavenging activities of $A$. erecta extract and fractions

\begin{tabular}{lccc}
\hline \multirow{2}{*}{ Sample } & \multicolumn{3}{c}{$\mathrm{EC}_{\mathbf{5 0}}(\boldsymbol{\mu \mathrm { g } / \mathrm { mL } )}$} \\
\cline { 2 - 4 } & $\mathrm{DPPH}$ & $\mathbf{N O}$ & $\mathbf{H}_{\mathbf{2}} \mathbf{O}_{\mathbf{2}}$ \\
\hline $\mathrm{ME}$ & $1758 \pm 26^{*}$ & $2182 \pm 118^{*}$ & - \\
$\mathrm{CF}$ & $535 \pm 2^{*}$ & $743 \pm 13^{*}$ & $387 \pm 49$ \\
$\mathrm{BF}$ & $532 \pm 9^{*}$ & $927 \pm 43^{*}$ & - \\
Positive control & $6 \pm 0$ & $279 \pm 5$ & $456 \pm 4$ \\
& (Quercetin) & (Quercetin) & (Gallic acid)
\end{tabular}

Data are presented as mean \pm SEM $(n=3)$. * indicates mean values that are significantly different $(p<$ 0.05) from that of the positive control, as determined by Student's T-test; -, activities undetectable

Table 3: Total phenolic and flavonoid contents of $A$. erecta extract and fractions

\begin{tabular}{ccc}
\hline Sample & $\begin{array}{c}\text { Total phenolic content } \\
\text { (mg GAE/ g) }\end{array}$ & $\begin{array}{c}\text { Total flavonoid content } \\
(\mathbf{m g} \mathbf{Q E} / \mathbf{g})\end{array}$ \\
\hline ME & $4.7 \pm 0.2^{\mathrm{a}}$ & $28.8 \pm 1.2^{\mathrm{a}}$ \\
CF & $12.9 \pm 0.6^{\mathrm{b}}$ & $67.5 \pm 2.1^{\mathrm{b}}$ \\
BF & $16.4 \pm 0.4^{\mathrm{C}}$ & $49.3 \pm 4.6^{\mathrm{C}}$ \\
WF & $1.5 \pm 0.1^{\mathrm{a}}$ & $0.8 \pm 0.0^{\mathrm{a}}$ \\
\hline
\end{tabular}

Data are presented as mean \pm SEM $(n=3)$. Values in the same column that are followed by different superscripts $(a-d)$ are significantly different $(p<0.05)$, as determined by Fisher's LSD test 
In this study, we demonstrated for the first time the $\mathrm{NO}$ and $\mathrm{H}_{2} \mathrm{O}_{2}$ scavenging ability of extract/fractions derived from an Avrainvillea species. Importantly, CF was as potent as gallic acid in scavenging $\mathrm{H}_{2} \mathrm{O}_{2}$, as evidenced by the lack of statistically significant difference between their mean values. Despite being a crude fraction, CF probably contained one or more highly potent natural antioxidants or $\mathrm{H}_{2} \mathrm{O}_{2}$ scavengers. Thus, future research to isolate and identify antioxidant compounds from CF is likely to be productive and is warranted. Our observation of the $\mathrm{NO}$ and $\mathrm{H}_{2} \mathrm{O}_{2}$ scavenging ability of CF suggests that $A$. erecta is a source of natural antioxidants that can be used to tackle biologically relevant free radicals. The ability of $\mathrm{CF}$ to scavenge $\mathrm{NO}$ is interesting; it implies that CF can be further explored to isolate potent antioxidants which may have protective effects against cellular nitrosative stress and/or NOmediated inflammatory diseases $[19,20]$.

Both CF and BF consistently had greater antioxidant activities compared with ME. On the other hand, WF consistently showed weaker antioxidant activities than ME. This implies that relatively non-polar and/or hydrophobic constituents of $A$. erecta have stronger antioxidant potential than the polar and/or hydrophilic constituents of the macroalga. Our observation corresponds with the finding that avrainvilleol, an antioxidant isolated from $A$. longicaulis, is non-polar and hydrophobic in nature $[10,18]$. Furthermore, our finding also suggests that future effort to identify potent antioxidants from $A$. erecta should focus on nonpolar and/or hydrophobic constituents.

Our results show that relative abundance of total flavonoids corresponds with the relative levels of $\mathrm{NO}$ and $\mathrm{H}_{2} \mathrm{O}_{2}$ scavenging activities as well as FRAP values in the extract/fractions of $A$. erecta. On the other hand, the relative total phenolic contents of the extract/fractions of $A$. erecta seem to correspond with DPPH scavenging activity. Hence, it is likely that flavonoids and other phenolic constituents were responsible for the antioxidant activity of $A$. erecta extract/fractions observed in this study. Our finding is in accordance with a correlation between antioxidant activity and phenolic and flavonoid contents that was observed in other green seaweeds [21].

\section{CONCLUSION}

Marine macroalga $A$. erecta is a promising source of potent antioxidants. Importantly, CF of $A$. erecta was as strong as pure gallic acid in scavenging $\mathrm{H}_{2} \mathrm{O}_{2}$. Compared with other solvent fractions tested, CF possessed the highest $\mathrm{DPPH}$ and $\mathrm{NO}$ radical scavenging activities as well as reducing power. CF had the highest flavonoid content, which suggests that relatively less polar flavonoids may be responsible for the antioxidant activity of the fraction. Further studies are needed to isolate and characterize the antioxidant principles of $A$. erecta, as well as verifying their bioactivity in cellular and animal models.

\section{ACKNOWLEDGEMENT}

This research was supported by Fundamental Research Grant Scheme (FRGS) of Ministry of Education, Malaysia.

\section{REFERENCES}

1. Mohamed S, Hashim SN, Abdul RH. Seaweeds: A sustainable functional food for complementary and alternative therapy. Trends Food Sci Tech 2012; 23(2): 83-96.

2. Madhusudan C, Manoj S, Rahul K, Rishi CM. Seaweeds: $A$ diet with nutritional, medicinal and industrial value. Res J Med Plant 2011; 5(2): 153-157.

3. Mohapatra L, Pati $P$, Panigrahy $R$, Bhattamisra SK. Therapeutic health booster: Seaweeds against several maladies. Indian J Geo-Mar Sci 2013; 42(5): 538-546.

4. Saad B, Sing YY, Nawi MA, Hashim N, Mohamed Ali AS, Saleh MI, Sulaiman SF, Talib KM, Ahmad K. Determination of synthetic phenolic antioxidants in food items using reversed-phase HPLC. Food Chem 2007; 105(1): 389-394.

5. Dessolin J, Schuler M, Quinart A, De Giorgi F, Ghosez L, Ichas $F$. Selective targeting of synthetic antioxidants to mitochondria: Towards a mitochondrial medicine for neurodegenerative diseases? Eur J Pharmacol 2002; 447(2-3): 155-161.

6. Yu R, Mandlekar S, Kong ANT. Molecular mechanisms of butylated hydroxylanisole-induced toxicity: Induction of apoptosis through direct release of cytochrome c. Mol Pharmacol 2000; 58(2): 431-437.

7. Tierney MS, Croft AK, Hayes M. A review of antihypertensive and antioxidant activities in macroalgae. Bot Mar 2010; 53(5): 387-408.

8. Zubia $M$, Robledo $D$, Freile-Pelegrin $Y$. Antioxidant activities in tropical marine macroalgae from the Yucatan Peninsula, Mexico. J Appl Phycol 2007; 19(5): 449-458.

9. Cho M, Kang IJ, Won MH, Lee HS, You S. The antioxidant properties of ethanol extracts and their solvent-partitioned fractions from various green seaweeds. J Med Food 2010; 13(5): 1232-1239.

10. Takamatsu S, Hodges TW, Rajbhandari I, Gerwick WH, Hamann MT, Nagle DG. Marine natural products as 
novel antioxidant prototypes. J Nat Prod 2003; 66(5): 605-608.

11. Dinh HL, Hori K, Quang NH. Screening and preliminary characterization of hemagglutinins in Vietnamese marine algae. J Appl Phycol 2009; 21(1): 89-97.

12. Shanmugam M, Mody KH, Ramavat BK, Murthy ASK, Siddhanta AK. Screening of Codiacean algae (Chlorophyta) of the Indian coasts for blood anticoagulant activity. Indian J Mar Sci 2002; 31(1): 33-38.

13. Ooh KF, Ong HC, Wong FC, Sit NW, Chai TT. High performance liquid chromatography profiling of health-promoting phytochemicals and evaluation of antioxidant, anti-lipoxygenase, iron chelating and anti-glucosidase activities of wetland macrophytes. Pharmacogn Mag 2014; 10(39): 443-455.

14. Chai TT, Wong FC. Whole-plant profiling of total phenolic and flavonoid contents, antioxidant capacity and nitric oxide scavenging capacity of Turnera subulata. J Med Plants Res 2012; 6(9): 1730-1735.

15. Ruch RJ, Cheng S-J, Klaunig JE. Prevention of cytotoxicity and inhibition of intercellular communication by antioxidant catechins isolated from Chinese green tea. Carcinogenesis 1989; 10(6): 1003-1008.

16. Waterhouse AL. Determination of total phenolics. Current Protocols in Food Analytical Chemistry, eds Wrolstad
RE, Acree TE, An H, Decker EA, Penner MH, Reid DS, Schwartz SJ, Shoemaker CF, \& Sporns $P$ (John Wiley \& Sons, Inc., New York), 2001; pp 11.1.1-I1.1.8.

17. Chang CC, Yang MH, Wen HM, Chern JC. Estimation of total flavonoid content in propolis by two complementary colometric methods. J Food Drug Anal 2002; 10(3): 178-182.

18. Sun HH, Paul VJ, Fenical W. Avrainvilleol, a brominated diphenylmethane derivative with feeding deterrent properties from the tropical green alga avrainvillea longicaulis. Phytochem 1983; 22(3): 743-745.

19. Li L, Hsu A, Moore PK. Actions and interactions of nitric oxide, carbon monoxide and hydrogen sulphide in the cardiovascular system and in inflammation - a tale of three gases! Pharmacol Ther 2009; 123: 386-400.

20. Hooper DC, Bagasra O, Marini JC, Zborek A, Ohnishi ST, Kean $R$, Champion JM, Sarker $A B$, Bobroski L, Farber JL, et al. Prevention of experimental allergic encephalomyelitis by targeting nitric oxide and peroxynitrite: implications for the treatment of multiple sclerosis. Proc Natl Acad Sci USA 1997; 94: 25282533.

21. Farasat M, Khavari-Nejad RA, Nabavi SMB, Namjooyan F. Antioxidant activity, total phenolics and flavonoid contents of some edible green seaweeds from northern coasts of the Persian gulf. Iran J Pharm Res 2014; 13(1): 163-170. 